\title{
Encouraging Independent Thought and Learning in First Year Practical Classes
}

\author{
P. B. Cranwell, ${ }^{*}$ F. J. Davis, J. M. Elliott, J. E. McKendrick, E. M. Page, \& M. J. Spillman \\ Department of Chemistry, University of Reading, Whiteknights, Reading RG6 6AD, United Kingdom \\ *Corresponding Author: p.b.cranwell@reading.ac.uk
}

Keywords: Practical Classes; First year; Transition; Open-Ended Investigation

\begin{abstract}
The transition from A-level to degree-level practical classes then to a research project, hence from dependent learner to independent researcher, is a hurdle that all students face when studying for a chemistry degree. This can be daunting so any innovations that aid this transition are of great value. At the University of Reading, the first year practical course has been redesigned to facilitate this transition by embedding independent thought and experimentation across all chemistry disciplines (introductory, organic, inorganic and physical). Examples of experiments that provide opportunities for independent student investigation, along with student perceptions of the experiments of the course, are given. Using this model for practical-class delivery, student engagement, confidence, independence and ultimately preparedness for year 2 were improved.
\end{abstract}

\section{Introduction}

The acquisition of a range of practical skills is an essential component in the process of becoming a professional chemist. As part of accreditation the Royal Society of Chemistry (RSC) requires students to complete a minimum number of hours of practical work throughout their studies (RSC, 2014).

Practical classes provide an opportunity for students to put into practise the theoretical concepts and ideas they have learned, essentially "learning by doing". This has been referred to as experiential, or active, learning (Felicia, 2011; Bonwell \& Eison, 1991), which importantly can lead to deeper learning and understanding (Fullan \& Langworthy, 2014; Ryan et al., 2009). It has been suggested that within a well-designed laboratory course, problem-based learning (PBL) and/or openended investigation, should be incorporated where possible, allowing students to explore their previous knowledge and further compound their learning (McGarvey 2004; McDonnell et al, 2007). PBL provides an excellent platform for encouraging independence, improving students' confidence and self-awareness, and preparing them for careers after their university studies, where they may well be expected to work through problems alone or in small teams.

With an increasingly diverse student body, a typical cohort may have studied a variety of post-16 courses and may include international students, all of whom will have differing competencies at entry. Depending upon students' previous experiences, the amount of practical work covered can vary widely.

A recent survey found that $13 \%$ of first year entrants had previously undertaken practical work twice a week, $35 \%$ once a week, $37 \%$ once every two weeks and $15 \%$ less than once a month (Page, 2016). In addition, the number of hours spent per week on practical work varied from 4 or more hours per week $(12 \%$ of students) to less than 0.5 hours per week $(15 \%$ 
of students), with some not completing any practical work at all. Many first-year entrants into our course undertook only one hour of practical work per week (38\%) (Page, 2016).

A report by SCORE: Science Community Representing Education (2008) looked into some of the challenges faced by teachers in delivering practical work. Practical work in a school environment needs to be controlled due to curriculum content and cost pressures for equipment and other resources, therefore greatly reducing the opportunity for independent thought and investigation by students. In addition, it is likely that timetabling may only allow for one or two hours of practical work per session (SCORE 2008; Smith, 2012), whereas in HE, upwards of four hours are normal. These constraints may well have impacted on students' previous lack of practical experience.

\section{Our students' experience}

Reflecting on the student experience in our existing course revealed, that for many students, the first and second year had become an exercise in acquiring marks rather than forming an integral part of becoming a chemist and developing the ability to think and work independently. Academics became familiar with students completing expository style classes (Domin, 1999), following instructions step-by-step rather than grasping the overall purpose of an experiment and the reason for each operation within it, possibly because their previous experiences had limited their exposure to independent investigation. We realised that this lack of investigative work was having an impact on students' confidence in the laboratory, and that this adversely affected their preparedness for research projects in the final year where a certain amount of independence is expected. We realised that in order to enhance student engagement, attainment and ultimately employability, we needed to provide students with the opportunity to undertake investigative practical work from the very beginning of their studies. Through careful course design, we believed that we could smoothly facilitate the transition from dependent to independent learner and researcher, and encourage students to take control of an experimental procedure and outcome.

\section{Laboratory Skills for Chemists (CH1PRA)}

The course discussed herein is the first year practical course, CH1PRA (20 credits) containing four sub-sections: introductory, inorganic, organic and physical, each of which runs for 4 hours per week, over five weeks.

Considering the diversity of our incoming students in terms of previous practical experience, vide supra, we decided to assume only basic knowledge upon entry. We therefore designed the course such that, in addition to teaching key practical skills, including interpretation of experimental data, completing risk assessments, and competence in a range of practical techniques, independent investigation was encouraged. We believed that upon completion students would also be acquainted with the generic skills required in year 2 and beyond. These softer, generic skills are of equal importance to students whether or not they are employed in chemistry-related jobs upon graduation. Examples of these skills include report writing, planning and designing experiments, problem-solving, team-working, independent learning and time-management (Hanson \& Overton, 2010).

\section{CH1PRA: Introductory Course}

It was decided the first practical class students undertook would be based upon thin layer chromatography (TLC), a common method of reaction monitoring covered at A-level that is frequently used in later years of studies. It was anticipated that this approach would avoid compartmentalisation of previous work (Taber, 1998), and allow students to see the link between their previous education and university, aiding this transition. Within this topic, students have the opportunity to think scientifically and truly experiment to solve a problem in a reasonably safe environment, something that many had not previously experienced. The task involves separation of three structurally related compounds using TLC analysis; $m$-cresol, $p$-cymene and thymol (Figure 1). Students are given the structures of these materials and a worksheet, but are told that, although there are instructors and demonstrators present, they will be given minimal guidance and are expected to experiment to determine a suitable eluent to separate the compounds and determine their $R_{f}$ values. 


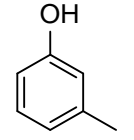

$m$-cresol

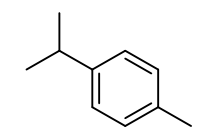

p-cymene

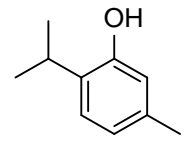

thymol
Figure 1 Structures of $m$-cresol, $p$-cymene and thymol

Students engaged well with this experiment, although they were reticent at first, possibly due to a lack of practical freedom encountered previously. Through discussions with their instructors they started to relate the physical properties of solvents and substrates to the outcome of the experiment. This provides a valuable exercise for students because this is most likely the first time that have seen more than one solution to a problem.

The remaining four weeks in the introductory block are dedicated to ensuring students become familiar with techniques they will use later in their degree, for example distillation, heating under reflux and recrystallization.

\section{CH1PRA: Inorganic}

The inorganic aspect of the practical course contains an open-ended experiment that students complete alongside their allocated practical experiments. Students are expected to correctly identify 19 inorganic compounds using simple chemical techniques and no reagents other than the unknowns, deionised water and concentrated $\mathrm{HCl}$ (for flame tests). Students are provided with a list of compounds they have to identify, and are advised to devise a flow chart detailing their strategy. They are encouraged to use reference material such as Vogel's Qualitative Inorganic Analysis and solubility data (Svehla, 1996). Once the flow chart has been checked and graded, students are given the unknowns to identify.

Although initially daunted, once students start to apply their knowledge and understanding, they are usually successful and feel a great sense achievement on completion. Successful students are those who spend time carefully planning their approach and are logical and organised both in their methodology and their observations. This teaches students the importance of preparation and pre-lab activities in practical work. In course evaluations this experiment is often cited as being the most stimulating and engaging. One student claimed:

\section{"...it was challenging and different from any} other thing we did and we all really enjoyed

it. It was helpful because we got to research and learn many different reactions so I'd say that it prepared us for [the second] year."

\section{CH1PRA: Organic}

Within the organic segment an alternative structure has been adopted wherein students work toward a focal point experiment rather than carrying out an open-ended practical, although the intended pedagogical outcomes are the same. This course structure is repeated in the second year, where there is another focal point experiment, albeit a more demanding one (Cranwell et al. 2015; Cranwell, 2016). This approach allows disparate techniques to be taught individually e.g. crystallization and reflux, then brought together so that students see these key skills in context, which is important for maintaining interest and engagement (Ramsden, 1997). The focal point experiment in Year 1 is a 3-step synthesis that runs over two weeks, Scheme 1 as shown in figure 2 (Cranwell, Harwood \& Moody, 2017).

During this experiment help offered by supporting staff is subtly minimized, encouraging students to work more independently and to learn to manage their time effectively. An organised student can complete the majority of the practical work in the first week, leaving the second week to collect any outstanding data and start the report. This specific experiment presents a good opportunity to work with students on the safe handling of toxic and corrosive chemicals, whilst the reactions themselves afford an opportunity for the instructor to address significant first year subjects encountered in lecture courses.

This experiment was well-received by students with one student commenting:

"I liked the two-week organic experiment because it gave us a good idea of how to manage time and it was nice to know what we were doing during the second week." 


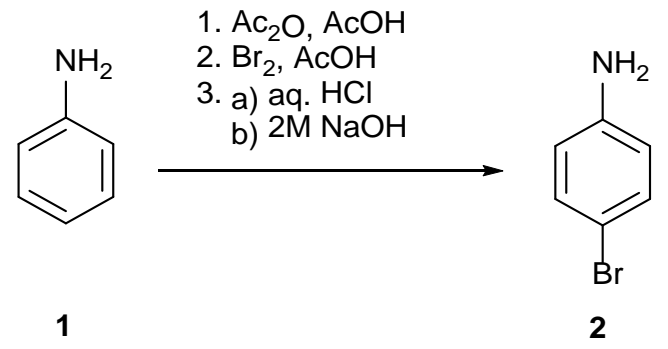

Figure 2 'Scheme 1' the focal point experiment used in Year 1.

\section{CH1PRA: Physical}

In the physical section of the course the emphasis is on observation and reporting, and the practical booklet is deliberately vague on details such as concentrations, timings etc. This requires students to use their own judgement and trial and error in determining experimental parameters.

This section includes an open-ended investigation based on thermodynamics. The task involves determining the enthalpy change associated with a solid melting, $\Delta_{f u s} H$. Students are given a list of available equipment and some back-ground information, along with the relevant theoretical equations. They are expected to design their own experimental procedure, using the relevant literature if they wish, ensuring it can be completed during the allotted time. They must discuss their approach with an instructor before starting.

Students are then required to fully analyse their data, determine the error, and compare their experimental value with the literature value. Finally, they reflect upon how their experiment could be improved. During this practical students learn to experiment through trial and error, reflecting upon previous results to influence a next step, and are encouraged to engage with the literature. This skill becomes increasingly important as a student transitions to a thorough, methodical, independent researcher.

\section{Conclusions}

Through the carefully considered inclusion of open-ended or focal-point experiments into the first-year practical course, we believe that students are successfully prepared for progression to the more complex practical work of Year 2 and beyond; the transition from dependent learner to independent researcher has commenced. Students have been exposed to a range of experiments where the concepts of independent thought and investigation are core themes; they are encouraged to investigate an open-ended problem, albeit in a semi-controlled environment. Students could see that their practical ability had improved over the first year, which had a noticeably positive effect on their confidence and engagement that was noticed by staff. One student stated:

"I think the first year practical course was
great; everyone else in the year enjoyed it
too... The introductory course was also
really good; I think it gave us a good
understanding of different techniques and
we were more confident. I found physical
and inorganic labs good as every week we
would do something completely different
and it was fun (and colourful)."

The incorporation of an open-ended practical at the very beginning of the year was a steep learning curve that the students initially disliked, presumably because it was a large deviation from the practical procedures that they had previously encountered. However, when surveyed following the module students actually appreciated the opportunity to undertake some investigative work and this provided an excellent ice-breaker for the new students as it encouraged them to talk to their peers.

The adoption of investigative experiments in each section of the course has produced students that are more independent, have increased confidence and are competent in a wide range of practical techniques as witnessed both anecdotally and through module evaluation comments. This has had a positive effect both in terms of students' chemical understanding, and also in terms of generic skills required up to graduation and beyond.

\section{Acknowledgements}

The authors would like to thank the students who participated in the practical classes as we were developing the practical work. We would also like to thank Dr Suzanne Fergus for her helpful comments when preparing the manuscript. 
Handouts for all experiments are included in the Appendices of this article.

\section{References}

Bonwell, C.C., \& Eison, J.A. (1991), Active Learning: Creating Excitement in the Classroom, ASHE-ERIC Higher Education Report No. 1. Washington DC: The George Washington University, School of Education and Human Development (PDF).

ISBN 1-878380-08-7

files.eric.ed.gov/fulltext/ED336049.pdf

Cranwell, P.B., Peterson, A.M., Littlefield B.T. R. \& Russell, A.T. (2015) An Operationally Simple Sonogashira Reaction for an Undergraduate Organic Chemistry Laboratory Class. Journal of Chemical Education 92, 1110-1114.

DOI: 10.1021/acs.jchemed.5b00030

Cranwell, P. (2016) Redesign of an Organic Chemistry Laboratory Course to Enhance Student Engagement. Unpublished dissertation, University of Reading.

Cranwell, P.B., Harwood, L.M. \& Moody, C.J. (2017), Experimental Organic Chemistry. Chichester: Wiley, $3^{\text {rd }}$ edition.

ISBN: 978-1-119095238-1

Domin, D.S. (1999) A review of laboratory instruction styles. Journal of Chemical Education, 76, 543-547.

DOI: 10.1021/ed076p543

Felicia, P. (2011) Handbook of Research on Improving Learning and Motivation Through Educational Games. Hershey, Pennsylvania; Information Science Reference.

ISBN: 978-1609604950

DOI: $10.4018 / 978-1-60960-495-0$

Fullan, M. \& Langworthy, M. (2014), A Rich Seam: How New Pedagogies Find Deep Learning. London, UK: Pearson.

ISBN: 9780992422035

http://www.michaelfullan.ca/wp-

content/uploads/2014/01/3897. Rich Seam w $\underline{\text { eb.pdf }}$

Hanson, T. \& Overton, T. (2010), Skills required by new chemistry graduates and their development in degree programmes (PDF).
ISBN: 978-1-903815-29-8

http://www.rsc.org/learn-

chemistry/resources/business-skills-and-

commercial-awareness-for-

chemists/docs/skillsdoc1.pdf

McDonnell, C., O'Connor, C. \& Seery M.K. (2007), Developing Practical Chemistry Skills by Means of Student-Driven Problem Based Learning Mini-Projects. Chemistry Education Research and Practice, 8, 130-139.

DOI: 10.1039/B6RP90026G

McGarvey D. (2004), Experimenting with Undergraduate Practicals, University Chemistry Education, 8, 58-65.

http://www.rsc.org/images/p4 mcgarvey tcm1 8-31151.pdf

Page, E. (2016), unpublished results, University of Reading.

Ramsden, J.M. (1997), How does a context based approach influence understanding of key chemical ideas at 16+?, International Journal of Science Education, 19, 697-710. DOI: $10.1080 / 0950069970190606$

Royal Society of Chemistry (2014), Accreditation of Degree Programmes (PDF). http://www.rsc.org/Education/courses-andcareers/accredited-courses/

Ryan, M.T., Baird, A.W., Mulholland, C.W. \& Irwin J. A. (2009), Practical Classes: A Platform for Deep Learning? Overall Context in the FirstYear Veterinary Curriculum, Journal of Veterinary Medical Education, 36, 180-185. DOI: 10.3138/jvme.36.2.180

SCORE: Science Community Representing Education (2008), Practical Work in Science: A report and proposal for a strategic framework. London: SCORE, (accessed May 2017).

http://www.scoreeducation.org/media/3668/report.pdf

Smith, C.J. (2012), Improving the school-touniversity transition: using a problem-based approach to teach practical skills whilst simultaneously developing students' independent study skills, Chemistry, Education, Research and Practice, 13, 490499.

DOI: 10.1039/C2RP20096A 
Taber K. S. (1998), The sharing

attraction: or 'I can't think about physics in chemistry', International Journal of Science

Education, 20, 1001-1014

DOI: $10.1080 / 0950069980200807$
- out of sucedtar S. (1996), Vogel's Qualitative Inorganic Analysis. England: Addison Wesley Longman Ltd, $7^{\text {th }}$ edition.

ISBN: 0582218667 


\title{
Appendix 1: Inorganic Experiment
}

\section{INORGANIC EXPERIMENT: IDENTIFICATION OF UNKNOWN SAMPLES}

You are provided with a sample of each of the following in tubes labelled 1-19. They are listed in alphabetical order:

\author{
Aluminium oxide, $\mathrm{Al}_{2} \mathrm{O}_{3}$ \\ Aluminium sulphate, $\mathrm{Al}_{2}\left(\mathrm{SO}_{4}\right)_{3}$ \\ Ammonium hydroxide $2 \mathrm{M} \mathrm{NH}_{4} \mathrm{OH}$ \\ Ammonium sulphate, $\left(\mathrm{NH}_{4}\right)_{2} \mathrm{SO}_{4}$ \\ Barium chloride, $\mathrm{BaCl}_{2}$ \\ Calcium nitrate, $\mathrm{Ca}\left(\mathrm{NO}_{3}\right)_{2}$ \\ Calcium oxide, $\mathrm{CaO}$ \\ Copper(II) oxide, CuO \\ Copper(II) sulphate, $\mathrm{CuSO}_{4}$ \\ Magnesium sulphate, $\mathrm{MgSO}_{4}$ \\ Manganese(IV) oxide, $\mathrm{MnO}_{2}$ \\ Potassium iodide, $\mathrm{KI}$ \\ Silver nitrate solution, $0.1 \mathrm{M} \mathrm{AgNO}_{3}$ \\ Sodium carbonate, $\mathrm{Na}_{2} \mathrm{CO}_{3}$ \\ Sodium dithionite, $\mathrm{Na}_{2} \mathrm{~S}_{2} \mathrm{O}_{4}$ \\ Sodium thiosulphate, $\mathrm{Na}_{2} \mathrm{~S}_{2} \mathrm{O}_{3}$ \\ Sulphuric acid $2 \mathrm{M}, \mathrm{H}_{2} \mathrm{SO}_{4}$ \\ Zinc carbonate, $\mathrm{ZnCO}_{3}$ \\ Water
}

Without the use of any additional reagents (except deionised water, and concentrated $\mathrm{HCl}$ for flame tests) identify the samples. Clearly indicate all the observations and deductions you make.

N.B. This experiment can be carried out in spare time throughout your Inorganic practical course and completed before the end of the session. You will have one whole session dedicated to this practical but the rest of the work should be fitted in around your other experiments. You should plan your strategy for identifying these samples and discuss this with your demonstrator before commencing the practical work.

Your set of unknowns should be returned to the stores at the end of the practical session.

You may carry out flame tests, but only after you have carried out some other preliminary tests.

For information, consult Vogel "Qualitative Inorganic Analysis". This experiment uses simple, (positively old-fashioned!) chemistry, but it is also an exercise in strategic thinking. You are to develop a logical approach to the problem, using the hints provided.

Draft your strategy in your laboratory notebook before embarking on the tests. A flow diagram is a good way to represent this. Record all your observations and deductions in your laboratory notebook before transferring your final conclusions to this practical booklet.

The marking scheme for this experiment is that you get half a mark for each correctly identified sample and there is a bonus half mark for correctly identifying all of the samples. Twenty marks are given for 
devising a clear and logical strategy for the sample identification and for displaying this in the form of your flow chart.

\section{Health and Safety:}

You MUST be complete a COSHH form before the experiment is undertaken. It can be completed either before the lab class or at the beginning of the session. You are expected to complete the hazard associated with each reagent used and also a precautionary statement. The risk information for all materials can be found in the Sigma Aldrich catalogue (available in the lab) or on the Sigma Aldrich website. You will need to search for each of the compounds identified and read its Safety Data (SDS) statement. You should note down the hazard ( $\mathrm{H}$ and $\mathrm{R}$ codes) and any precautionary statements ( $P$ and $\mathrm{S}$ codes). If no precautionary statements are present you should use 'wear appropriate PPE (Lab coat, safety glasses and gloves)' in this section.

The declaration at the bottom must be signed by you and be countersigned by the demonstrator before you start the experiment. 


\section{Appendix 2: Preparation of $p$-Bromoaniline}

\section{Preparation of $p$-Bromoaniline}

In organic synthesis, the preparation of compounds with a defined structure as efficiently and quickly as possible is the major goal. This often requires a great deal of skill and knowledge on the part of the chemist undertaking the synthesis.

Route for preparing compounds that consist of more than one step and are termed "linear syntheses" as there are many operations after each other. The overall yield of the transformations drops quickly with each reaction step:

$$
\text { A } \underset{90 \%}{\longrightarrow} \text { B } \underset{90 \%}{\longrightarrow} \text { C } \underset{90 \%}{\longrightarrow} \text { D }
$$

If each step yielded $90 \%$, after the 3 steps depicted the overall yield would only be $73 \%(0.9 \times 0.9 \times$ $0.9)$.

Routes in which molecules are prepared in parallel by two routes, then the two fragments are joined at the end of the synthesis, are termed "convergent". Convergent syntheses are generally more efficient than linear syntheses.

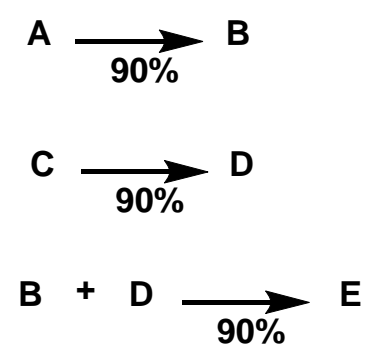

To make $\mathbf{B}$ and $\mathbf{D}$ is $90 \%$ for each step. Joining $\mathbf{B}$ and $\mathbf{D}$ then gives a yield of $81 \%$ which is much more favourable.

The exercise today will require 1.5 weeks to complete. If yields are not sufficient for continuation of the synthesis then you may need to repeat the step. 


\section{COSHH Form}

The information MUST be read before the experiment is undertaken.

The declaration form at the bottom of the sheet MUST be signed by you and be COUNTERSIGNED by the demonstrator BEFORE you start the experiment.

DO NOT sign this form until you are satisfied you appreciate the hazards associated with all aspects of this experiment.

\begin{tabular}{|l|l|l|}
\hline \multicolumn{1}{|c|}{ Chemical } & \multicolumn{1}{c|}{ Hazard } & \\
\hline Aniline & & \\
\hline Acetic anhydride & & \\
\hline Glacial acetic acid & & \\
\hline Ethanol & & \\
\hline Acetanilide & & \\
\hline Bromine & & \\
\hline 4-Bromoacetanilide & & \\
\hline $\begin{array}{l}\text { Hydrochloric acid } \\
\text { (conc.) }\end{array}$ & & \\
\hline $\begin{array}{l}\text { Sodium hydroxide } \\
\text { (25\% aq. Soln.) }\end{array}$ & & \\
\hline 4-Bromoaniline & & \\
\hline
\end{tabular}

I have read the experimental procedure and the hazards assessments and will comply with these procedures.

Student:

Date:

Demonstrator: 
The overall transformations you will undertake are as follows:

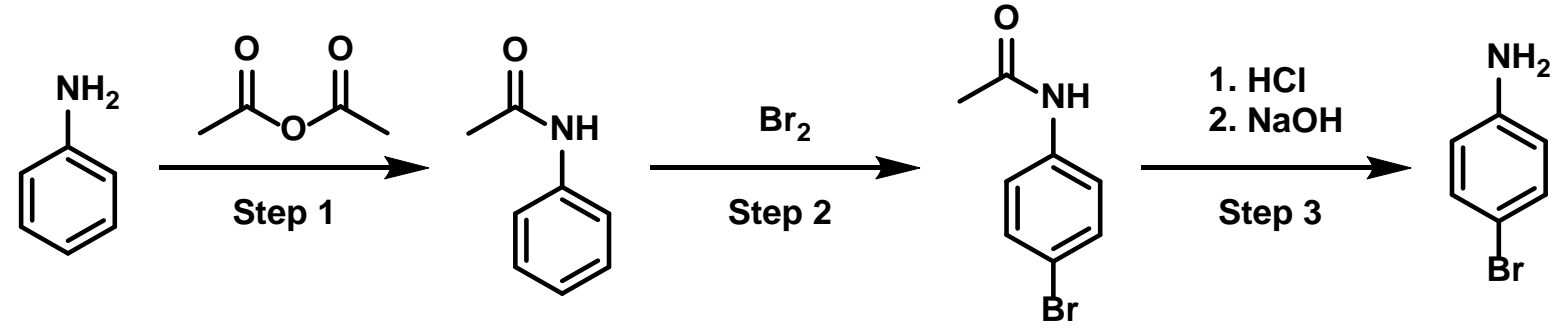

All glassware used needs to be washed thoroughly with acetone then with distilled water and placed on the trolley in the appropriate place. At no point should any compounds be placed in the general waste. Aqueous waste is put into the aqueous waste containers. Organic solvent waste (ethyl acetate, acetone) can be placed in the non-halogenated waste container. UNDER NO CIRCUMSTANCES SHOULD THE AQUEOUS AND ORGANIC WASTE BE MIXED.

\section{Procedure Step 1:}<smiles>CC(=O)OC(=O)CCC(=O)Nc1ccccc1</smiles>

\begin{tabular}{|c|c|c|c|}
\hline Materials & Hazards & Precaution & Quantity \\
\hline Aniline & Toxic, carcinogenic & $\begin{array}{c}\text { Wear gloves, work in a } \\
\text { fume hood }\end{array}$ & $10 \mathrm{~mL}$ \\
\hline Acetic Anhydride & Corrosive, irritant & Wear gloves & $12 \mathrm{~mL}$ \\
\hline Glacial Acetic Acid & Corrosive, irritant & Wear gloves & $25 \mathrm{~mL}$ \\
\hline
\end{tabular}

In a $100 \mathrm{~mL}$ RBF place $10 \mathrm{~mL}$ of aniline then add $25 \mathrm{~mL}$ acetic acid followed by $12 \mathrm{~mL}$ acetic anhydride. Care - this is exothermic!. Stopper the flask and shake the reaction thoroughly. Allow the mixture to stand at room temperature for 5 minutes and then dilute with 100-200 mL water until the product crystallizes. When crystallization is complete, filter the mixture by Büchner filtration, wash the crystals with water and allow to dry for 10 minutes by sucking air over the crystals.

This crude material is clean enough to use directly in stage 2 without further purification.

Take $5 \mathbf{g}$ into stage 2 and recrystallize the remainder from hot ethanol, dry, weigh, take the melting point, an IR and keep a sample for inspection.

\section{Procedure Step 2:}<smiles>CC(=O)Nc1ccc(Br)cc1</smiles> 


\begin{tabular}{|c|c|c|c|}
\hline Materials & Hazards & Precaution & Quantity \\
\hline Acetanilide (stage 1) & $\begin{array}{c}\text { Unknown, treat as } \\
\text { toxic }\end{array}$ & $\begin{array}{c}\text { Wear gloves. Use } \\
\text { ONLY in a fume hood. }\end{array}$ & $5 \mathrm{~g}$ \\
\hline Bromine & $\begin{array}{c}\text { Highly corrosive, } \\
\text { irritant }\end{array}$ & $\begin{array}{c}\text { Wear Marigold gloves. } \\
\text { Use ONLY in a fume } \\
\text { hood. }\end{array}$ & $2.1 \mathrm{~mL}$ \\
\hline Glacial Acetic Acid & Corrosive, irritant & Wear gloves & $25+30 \mathrm{~mL}$ \\
\hline Sodium metabisulfite & Irritant & & $2 \mathrm{~g}$ \\
\hline
\end{tabular}

Bromine is highly corrosive and should be treated with care. Use ONLY in a fume hood. It should only be carried in a secondary container and you should only use it with Marigold gloves. Any glassware that is contaminated with bromine should be wash with aqueous sodium thiosulfate solution. Any spillages should be treated with aqueous thiosulfate solution. Ask a demonstrator before proceeding with the bromine.

In a $250 \mathrm{~mL}$ conical flask, dissolve $5 \mathrm{~g}$ of the acetanilide from the previous step in $25 \mathrm{~mL}$ cold glacial acetic acid. In a conical flask, mix up a solution of $2.1 \mathrm{~mL}$ bromine in $30 \mathrm{~mL}$ glacial acetic acid and add it slowly to the acetanilide solution, shaking the flask constantly the ensure mixing. Let the mixture stand at room temperature for 15 minutes then pour onto $300 \mathrm{~mL}$ cold water.

Filter off the precipitated product using Büchner filtration then return the solid to the original conical flask. Add $150 \mathrm{~mL}$ water and $2 \mathrm{~g}$ sodium metabisulfite (this removes any unreacted bromine and acetic acid). Filter the solid again by Buchner filtration, pressing the solid with a spatula to remove most of the liquid. Weigh your product.

The crude material is of sufficient purity to use in stage 3 . Take $5 \mathbf{g}$ onto stage 3.

Recrystallise the remainder by dissolving the crude solid in the minimum volume of hot ethanol and adding drops of water until the turbidity remains (if a brown colour persists at this stage add a little activated charcoal and run a filter paper whilst still hot). Filter the ensuing crystals by Büchner filtration and wash with ice cold ethanol. Dry in a $100{ }^{\circ} \mathrm{C}$ oven, weigh, measure the melting point and IR. Keep a sample for inspection.

\section{Procedure Step 3:}<smiles>CC(=O)Nc1ccc(Br)cc1</smiles> 


\begin{tabular}{|c|c|c|c|}
\hline Materials & Hazards & Precaution & Quantity \\
\hline $\begin{array}{c}p \text {-Bromoacetanilide } \\
\text { (stage 2) }\end{array}$ & $\begin{array}{c}\text { Unknown, treat as } \\
\text { toxic }\end{array}$ & Wear gloves \\
\hline $\begin{array}{c}\text { Conc. hydrochloric } \\
\text { acid }\end{array}$ & $\begin{array}{c}\text { Highly corrosive, } \\
\text { causes burns }\end{array}$ & $\begin{array}{c}\text { Wear gloves. Use } \\
\text { ONLY in a fume } \\
\text { hood. }\end{array}$ & $25 \mathrm{~mL}$ \\
\hline $\begin{array}{c}25 \% \text { sodium } \\
\text { hydroxide solution }\end{array}$ & $\begin{array}{c}\text { Corrosive, causes } \\
\text { burns }\end{array}$ & Wear gloves & \\
\hline
\end{tabular}

Place $5 \mathrm{~g} p$-bromoacetanilide into a $100 \mathrm{~mL}$ RBF then add $25 \mathrm{~mL}$ water followed by $25 \mathrm{~mL}$ concentrated $\mathrm{HCl}$ and a few antibumping granules. Fit a condenser to the flask (ask demonstrator if unsure) and heat at reflux until all the solid dissolves. After complete dissolution, continue to heat for a further 20 minutes. Allow the flask to cool to room temperature then cool in ice/water and carefully add the $\mathrm{NaOH}$ solution (care - exothermic) until the mixture is alkaline (use pH paper).

The product may separate as an oil, which will solidify upon cooling/scratching with a glass rod. When crystallization is complete, recover the solid by Büchner filtration. Dry on the filter paper for 10 minutes under suction. Record the weight of crude product, then recrystallize the solid from the minimum volume of hot ethanol. If the p-bromoaniline is badly discoloured add a small amount of activated charcoal and boil the solution for a few minutes and then gravity filter through a fluted filter paper in a filter funnel whilst hot. Add water dropwise to the hot ethanol solution until it becomes slightly turbid and then scratch the sides of the vessel with a glass rod until the $p$-bromoaniline begins to crystallize. Once crystallisation has begun, cool the flask on ice. Filter off the pure $p$-bromoaniline by Büchner filtration and wash the crystals with ice cold ethanol. Dry in a desiccator, weigh, take the melting point and an IR. Keep a sample for inspection.

\section{Questions:}

1. Why is aniline so reactive towards electrophilic aromatic substitution?

2. Why does the formation of the amide reduce the reactivity of the aniline?

3. Why is only the para-brominated product formed in step 2 ? 


\section{Appendix 3: Enthalpy of Fusion}

\section{Enthalpy of fusion: A PRACTICAL BASED PROBLEM SOLVING EXERCISE}

HAZARDS:

Chemical hazards:

Water - non hazardous;

Ice - non hazardous

\section{Physical hazards:}

Electrical equipment may cause electrocution. Hot surfaces may cause burns. Broken glassware may cause skin damage.

\section{Pre-lab work}

You must research the topic and come up with a protocol before the laboratory session your demonstrator needs to sign that it is acceptable before you start the experiment. You MUST complete a COSHH from and have it counter-signed before starting practical work.

\subsection{Introduction}

The enthalpy change associated with a solid melting is the enthalpy of fusion $\left(\Delta_{f u s} H\right)$. In this experiment you will measure the enthalpy of fusion of water. You will need to design an experiment to be performed during the allotted time that will allow this property to be determined. When a substance undergoes a phase change (ice to water for example) heat energy is required, this is the heat of fusion of water ( $Q_{\text {Phase change }}$ usually quoted as the heat required per gram of material). The amount of heat energy required depends on the mass of material $(m)$ and the nature of the material $\left(H_{f}\right)$ and will vary from one material to another. When ice melts to form water is absorbs heat energy from its surroundings (the water and the container), it takes about $334 \mathrm{~J}$ of heat for $1 \mathrm{~g}$ of ice to melt, and the temperature of the surrounding water is observed to decrease as the ice melts. When the ice first melts it forms water at $0{ }^{\circ} \mathrm{C}$ and this must then equilibrate to the temperature of the surrounding water and container, the observed temperature decrease is proportional to the total heat energy required $\left(Q_{\text {Total }}\right)$ and is therefore due to the sum of the latent heat of fusion $\left(Q_{\text {Phase change }}\right)$ and heat loss due to the equilibration process ( $\left.Q_{\text {Equilibration }}\right)$.

\begin{tabular}{|c|c|c|}
\hline Equation 1 & $Q_{\text {Total }}=\left(m_{\text {water }} \cdot C_{p} \cdot \Delta T_{\text {Total }}\right)$ & $\begin{array}{l}\text { Where } m_{\text {water }} \text { is the initial mass of water }(\mathrm{g}) \text {, } \\
C_{p} \text { is the specific heat capacity of the } \\
\text { surroundings, i.e. the water }\left(4.2 \mathrm{~J} \mathrm{~g}^{-1} \mathrm{~K}^{-1}\right) \text {, and } \\
\Delta T_{\text {Total is }}\left(T_{\text {Initial }}-T_{\text {Final }}\right) \text { the total } \\
\text { temperature change observed }(\mathrm{K}): \mathrm{g} \cdot \mathrm{J}^{-1} \cdot \mathrm{K}^{-1} \cdot \mathrm{K}^{-} \\
\left.{ }^{1} \mathrm{~K} \text { [note the units cancel to leave } \mathrm{J}\right]\end{array}$ \\
\hline Equation 2 & $Q_{\text {Phase change }}=\left(m_{\text {ice }} \cdot H_{f}\right)$ & $\begin{array}{l}\text { Where } m_{i c e} \text { is the mass of ice }(\mathrm{g}) \text { and } H_{f} \text { is the } \\
\text { latent heat of fusion of water: } \mathrm{g} . \mathrm{J}^{-1} \mathrm{~g}^{-1} \text { [note units } \\
\text { cancel to leave J] }\end{array}$ \\
\hline Equation 3 & $\begin{array}{l}Q_{\text {Equilibration }}= \\
\left(m_{\text {ice }} \cdot C_{p} \cdot \Delta T_{\text {Equilibration }}\right)\end{array}$ & $\begin{array}{l}\text { Where } m_{\text {ice }} \text { is the mass of ice }(\mathrm{g}), C_{p} \text { is the } \\
\text { specific heat capacity of the surroundings i.e. } \\
\text { the water }\left(4.2 \mathrm{~J} \mathrm{~g}^{-1} \mathrm{~K}^{-1}\right) \text {, and } \Delta T_{\text {Equilibration }} \text { is } \\
\left(T_{\text {Final }}-273\right): \mathrm{g} \cdot \mathrm{J}^{-1} \cdot \mathrm{g}^{-1} \cdot \mathrm{K}^{-1} \cdot \mathrm{K} \text { [note the units } \\
\text { cancel to leave J] }\end{array}$ \\
\hline
\end{tabular}




\begin{tabular}{|l|l|l|}
\hline Equation 4 & $\begin{array}{l}Q_{\text {Total }}=\left(Q_{\text {Phase change }}\right)+ \\
\left(Q_{\text {Equilibration }}\right)\end{array}$ & \\
\hline Equation 5 & $\begin{array}{l}\left(m_{\text {water }} \cdot C_{p} \cdot \Delta T_{\text {Total }}\right)= \\
\left(m_{\text {ice }} \cdot H_{f}\right)+ \\
\left(m_{\text {ice }} \cdot C_{p} \cdot \Delta T_{\text {Equilibration }}\right)\end{array}$ & $\begin{array}{l}\text { Equation } 5 \text { can be re-arranged to find the } \\
\text { latent heat of fusion of water, } H_{f} .\end{array}$ \\
\hline
\end{tabular}

\subsection{Experimental method.}

5.2.1 Design your experiment and outline the procedure in your lab book. You will have the following equipment at your disposal:

Weighing balance

Electrical heater/stirrer

Measuring cylinder

Pipette/pipette filler

Glass beaker

Thermometer

5.2.2 Ask your demonstrator to sign your proposed experimental COSHH form

\subsubsection{Carry out your experiment}

\subsection{Results}

Record your results in your lab notebook. Use the results collected to determine the enthalpy of fusion of water and compare your result with the theoretical value

\subsection{Conclusions and Sign-off}

You may discuss the theory and your findings with your peers, your demonstrator and staff. Draw suitable conclusions and take your lab book to your demonstrator for signing before leaving the lab. You must hand in your lab book at the end of this class. 


\section{Appendix 4: TLC}

\section{Week 1 - TLC Analysis}

In this practical class you will undertake TLC analysis to determine the identity of an unknown compound. The three compounds that you will be given are as follows:<smiles>Cc1cccc(O)c1</smiles>

m-Cresol<smiles>Cc1ccc(C(C)C)cc1</smiles>

p-Cymene<smiles>Cc1ccc(C(C)C)c(O)c1</smiles>

Thymol

\section{What is TLC?}

Thin layer chromatography (TLC) is an analytical technique predominantly used for determining the purity of materials and determining the progress of a chemical reaction. In TLC the adsorbent is supported as a thin coating on a flat surface which may be a glass plate or, more conveniently, a sheet of aluminium or plastic. The adsorbent (the white material on the surface of the plates) is silica, which contains $\mathrm{Si}-\mathrm{OH}$ bonds as shown.

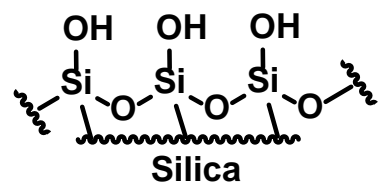

When TLC analysis is performed on a sample, the sample it will interact with these $\mathrm{OH}$ groups by intermolecular forces. The primary mode of interaction is through hydrogen-bonding, which is reasonably strong. Different functional groups will interact differently, leading to their separation.

\section{Question 1:}

Draw dipoles on the molecules below.<smiles>CCCC</smiles>

Which molecules can undergo hydrogen bonding? Give reasons for your answer. 


\section{Question 2:}

Consider the surface of the TLC plate (shown on the previous page). Draw two diagrams showing how ethanol will interact with the silica surface. Label one diagram with ethanol as the hydrogen bond donor, and one where it is the acceptor.

To collect TLC data, the sample is run up the plate using an eluent (the solvent). This eluent will pull the molecule up the plate over the surface of the silica, which leads to spots being distributed up the plate. If a compound can form a hydrogen bond with the silica surface it will move up the plate more slowly or, in other words, elute more slowly. When considering to what extent a compound will interact with the silica, you need to consider the polarity of the whole molecule rather than just the polar functional groups, and if any adjacent functional groups will affect the interaction of the molecule with the silica surface. For example a large group near to a hydrogen-bonding functionality will lead to less hydrogen bonding being possible.

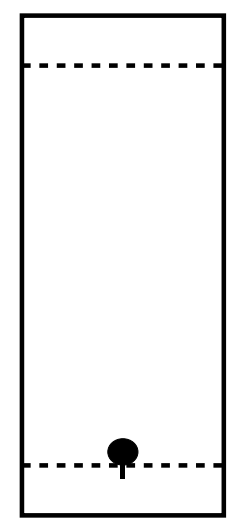

TLC plate at $\mathrm{t}=\mathbf{0}$

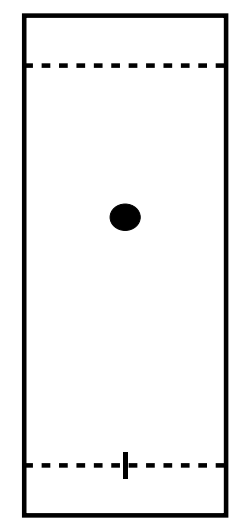

TLC plate after the sample has been run 


\section{Question 3:}

Considering the polarity of the three compounds that you have been given ( $m$-cresol, $p$-cymene and thymol), suggest which will elute the fastest and which will elute the slowest. Give reasons for your answer.

\section{Fastest:}

\section{Slowest:}

\section{Running a TLC:}

- The TLC plates:

The most useful size of plate for TLC analysis is one of about $8 \times 3 \mathrm{~cm}$ which permits up to four samples to be spotted onto the baseline (a pencil line marked about $1 \mathrm{~cm}$ from one end of the plate) and has sufficient length to give the best resolution in a convenient amount of time.

- The TLC tank:

The TLC tank is usually a jar that contains a piece of filter paper. The filter paper acts as a wick and ensures that the atmosphere inside the TLC tank maintains saturated with solvent.

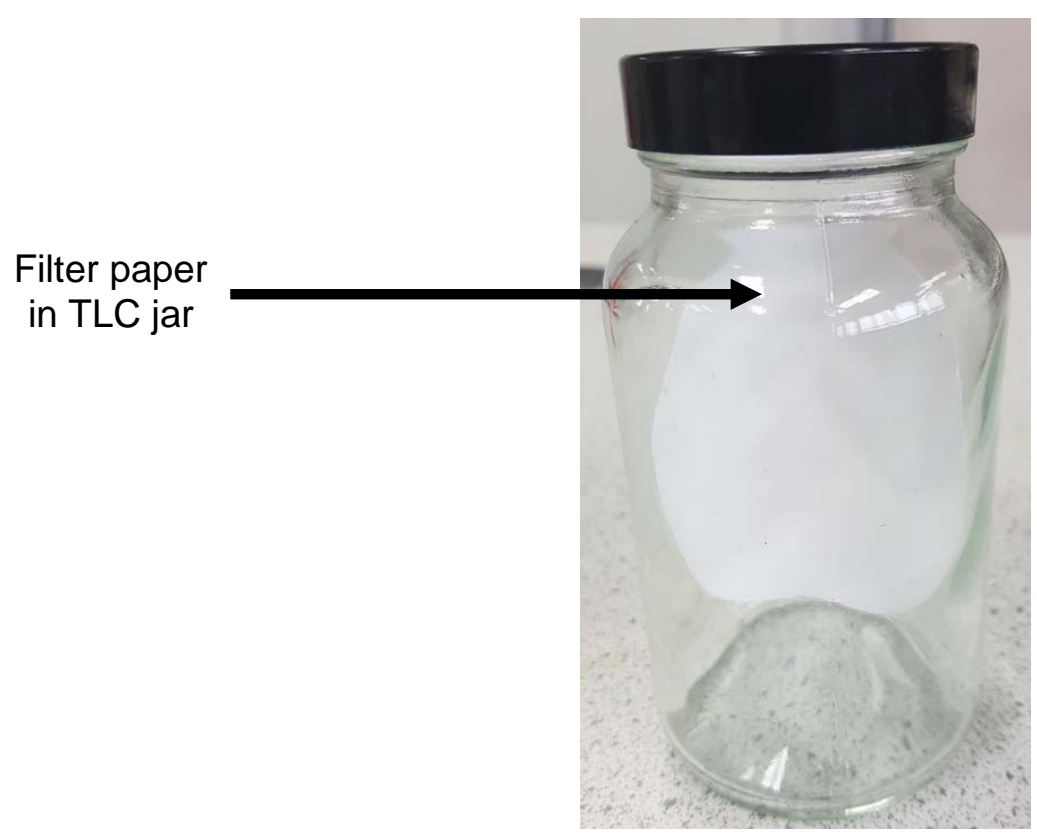


- Determining the eluent

This is possibly the most tricky part of the process; deciding upon an eluent to use for your sample. Experience is extremely useful here, but when you are first starting out the best way is by trial and error. There are, however, some useful things to know.

o More polar solvents elute the compound faster so it moves further up the TLC plate. Commonly used polar solvents include diethyl ether, ethyl acetate and methanol.

o Less polar solvents elute the compound more slowly. Commonly used less polar solvents are hexanes/petroleum ether and dichloromethane.

\section{Question 4:}

Why do you think that more polar solvents elute compounds more quickly, and less polar solvents elute compounds less quickly?

\section{Running a TLC 2:}

o Solvents usually come in pairs. Usually we mix a polar and a non-polar solvent to give a binary eluent. Some typical examples include: diethyl ether/pet. ether (least polar), ethyl acetate/hexanes (medium polarity) or methanol/dichloromethane (most polar).

o Often we use ratios of one solvent to the other. This has a marked effect on polarity for example, $100 \%$ pet. ether is non-polar so many compounds will not move off the baseline. $50 \%$ Diethyl ether/pet. ether is moderately polar, $50 \%$ ethyl acetate/pet. ether is more polar again and $10 \%$ methanol/dichloromethane is extremely polar. As a general rule, $50 \%$ diethyl ether/pet. ether is roughly equivalent to $20 \%$ ethyl acetate/pet. ether.

o Usually we make eluents up in $10 \mathrm{~mL}$ batches e.g. 50\% diethyl ether/pet. ether would be $5 \mathrm{~mL}$ diethyl ether and $5 \mathrm{~mL}$ hexanes.

Remember it is easier to start less polar, and then increase polarity of the eluent.

\section{Question 5:}

Place the following solvent systems in order of polarity, starting with the least polar. $10 \%$

$\mathrm{MeOH} /$ dichloromethane
$30 \%$ EtOAc/pet.

ether
$100 \%$ pet. ether

$10 \%$ diethyl

\begin{tabular}{|l|l|l|l|}
\hline Least polar & & & Most polar \\
\hline & & & \\
& & & \\
\hline
\end{tabular}




\section{Question 6:}

Considering the polarity of the samples, decide upon a solvent system that you are going to start with.

Initial solvent system:

Mix up $10 \mathrm{~mL}$ of this initial solvent system and pour it into the TLC chamber, ensuring that the chamber contains a filter paper.

\section{Making the TLC plate:}

In order to load a compound onto the plate, you will need to dissolve the sample in a solvent in which it is readily soluble as neat liquids are too concentrated, and solids are not suitable.

Place a small sample ( $m$-cresol, $p$-cymene and thymol; approx. 2 drops/crystals) of each compound in a labelled vial and dissolve each in $2 \mathrm{~mL}$ of ethyl acetate.

Next, take a TLC plate and lightly draw a line in pencil across the bottom about $1 \mathrm{~cm}$ up from the base. Then place 4 crosses (pencil marks) lightly on the baseline. Label the first one $m$-cresol $(A)$, the second as $p$-cymene (B), the third as thymol (C) and the final one "mixed".

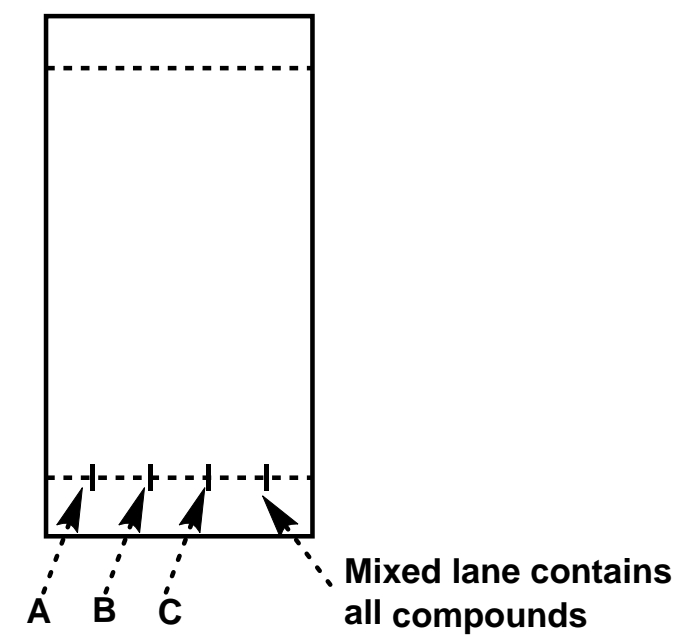

Loading the TLC plate:

Dip a spotter into the solution of $m$-cresol $(A)$ then touch the loaded pipette lightly onto the silica surface at the point marked $m$-cresol. This will cause some of the liquid in the pipette to be drawn onto the adsorbent, forming a visible ring of solvent. Blow gently on the plate to dry the spot. Place another spot of $m$-cresol on the fourth spot labelled "mixed". Repeat this procedure for $p$-cymene and thymol. Remember to keep the baseline spot as small as possible (TLC is an extremely sensitive procedure and it is very easy to overload the plates, which will lead to poor results).

\section{Running the TLC:}

Gently place the TLC plate into the TLC jar using tweezers, remembering to replace the lid, and allow the solvent to run up the plate until it is approximately $1 \mathrm{~cm}$ from the top. Remove the TLC plate from the chamber, mark the solvent front lightly with a pencil (DO NOT USE A PEN), and visualize it under UV light. You can circle your spots with a pencil. You might finish with something like this: 


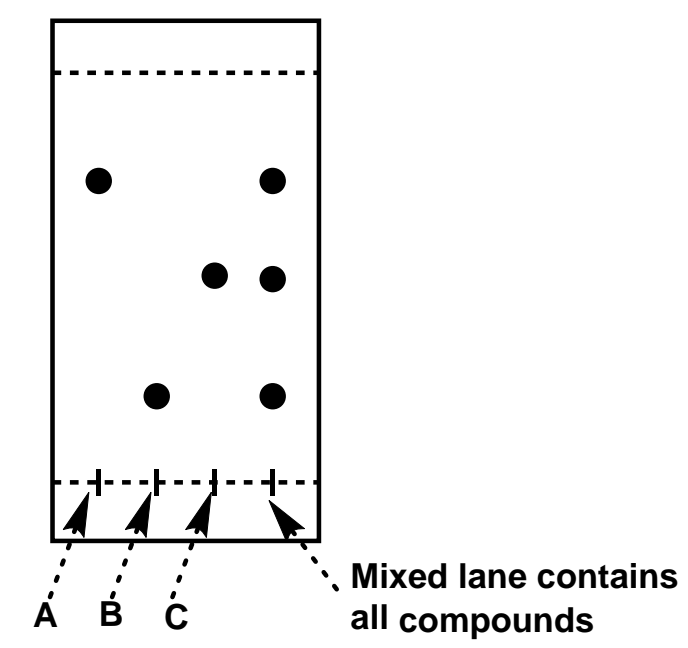

If you do not achieve good separation or your spots are all too high or too low, then adjust the eluent accordingly. If your spots are very large, you may need to run the TLC again making sure you add less sample to the TLC plate.

\section{Question 7:}

If your spots are all low down the plate, should the eluent be more or less polar? Explain your answer in terms of intermolecular forces.

If your spots are all high on the plate, the eluent should be more or less polar? Explain your answer in terms of intermolecular forces.

\section{Calculating the $\boldsymbol{R}_{\boldsymbol{f}}$ value:}

Once you have successfully separated all of the spots by adjusting the eluent, you need to calculate the $R_{f}$ value. When quoting an $R_{f}$ value you will need to state the solvent in which the sample was run.

The $R_{f}$ can be calculated according to the following equation:

$$
R_{f}=\frac{\text { Distance moved by the product spot }(\mathrm{mm})}{\text { Distance moved by the solvent front }(\mathrm{mm})}=\frac{\mathrm{b}}{\mathrm{a}}
$$

The $R_{f}$ value is always less than 1. A large $R_{f}$ value means the spot has moved a long way up the plate and a small $R_{f}$ value means it has not. 


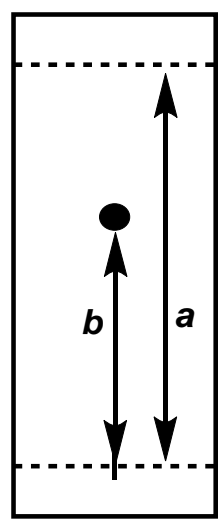

You should now know the $R_{f}$ value of each of the samples $m$-cresol (A), $p$-cymene (B) and thymol (C) and can now determine the identity of the unknown sample. To do this, repeat the steps given above. Make sure that you do not add too many spots to your TLC plate. You may need to run up to three TLC samples.

\section{Question 8:}

Determine the Rf values for your compounds:

$m$-cresol:

p-cymene:

Thymol:

Unknown:

\section{Question 9:}

The unknown compound is:

Explain your answer: 


\section{COSHH Form}

The information MUST be read before the experiment is undertaken. The declaration form at the bottom of the sheet MUST be signed by you and then be COUNTERSIGNED by the demonstrator BEFORE you start the experiment. DO NOT sign this form until you are satisfied you appreciate the hazards associated with all aspects of this experiment.

TLC analysis:

- $m$-Cresol is toxic if swallowed, is toxic in contact with skin and causes severe skin burns and eye damage.

Avoid all skin contact.

- $\quad p$-Cymene is flammable, causes skin, eye and respiratory irritation Avoid all skin contact.

- Thymol causes severe skin burns and eye damage. Avoid all skin contact.

- Ethyl acetate is highly flammable and toxic Avoid all sources of ignition and inhalation of the fumes.

- Hexane is flammable, possible risk of impaired fertility, possible carcinogen, neurotoxin

Avoid all sources of ignition, wear gloves and only use in a fume hood.

- Methanol is highly flammable, toxic if swallowed and in contact with skin, damages organs.

Avoid all sources of ignition, wear gloves.

- Diethyl ether is extremely flammable, may cause drowsiness and skin cracking. Avoid all sources of ignition, wear gloves.

- Dichloromethane causes skin, eye and respiratory irritation, possible carcinogen Avoid all skin contact.

I have read the experimental procedure and the hazards assessments and will comply with these procedures.

Student

Date:

Demonstrator: 